\title{
Development and initial validation of the Preschool Imitation and Praxis Scale (PIPS)
}

\author{
Marleen Vanvuchelen a,b,c, ${ }^{*}$, Herbert Roeyers d, Willy De Weerdt b \\ a Department Health Care, PHL University College, Belgium \\ b Department of Rehabilitation Sciences, K.U.Leuven, Belgium \\ c Department of Physiotherapy, V.U.B., Belgium
}

a Research Group Developmental Disorders, Ghent University, Belgium

\begin{abstract}
A B S TRACT
The goal of this study was to develop and subsequently evaluate the internal construct and criterion-related validity of the Preschool Imitation and Praxis Scale (PIPS). Different task characteristics were selected considered to be important as unravelled in research in apraxic adults to tap a broad range of possible imitation mechanisms. Participants included 498 children without disabilities (1-4.9 years) and 47 children with autism spectrum disorders (ASD) (1.9-4.5 years). Exploratory factor analysis disclosed 4 dimensions in the scale, labelled: goal directed versus non-goal directed procedural imitation and single versus sequential bodily imitation. Internal consistency for the PIPS scale $(\mathrm{a}=.97)$ and subscales was high (a ranged from .79 to .96$)$. In both samples, the PIPS scale score was strongly related to age $(r=.78$, respectively $r=.56)$. Significant relationships between the PIPS score and mental, language, motor ages in the ASD sample supported criterion-related validity ( $r$ ranged from .59 to .74). The PIPS appears to have fundamentally sound psychometric characteristics, although more research is needed.
\end{abstract}




\section{Introduction}

Imitation is the capacity of an individual to replicate an observed behaviour. It involves the ability to transform perceptual information into a motor copy of it (Prinz, 2002). A more restrictive description of 'true' imitation requires that a novel action is learned by observing someone else performing it, and in addition to novelty, it requires a means/ends structure (Tomasello, Carpenter, Call, Behne, \& Moll, 2005). In young children, imitation is central to learn social behaviour and skilled acts or praxis (Masur, 2006). Imitation avoids time-consuming trialand-error learning. In reproducing the exact and detailed features of the demonstrator's actions, children are likely to successfully complete the intended actions, even with a limited understanding of their purpose. Moreover, faithful copying can be used to disentangle the goal of an action to be imitated when it is not completely clear to the observer or to learn about initially opaque aspects of causality (Lyons, Young, \& Keil, 2007). Accumulating evidence from behavioural studies in typically developing children suggests that imitation is not a onedimensional, but a polymorphous phenomenon. Imitation can have many forms depending on distinct action types. Neonates imitate facial movements, in particular tongue protrusion, and simple gestures (Meltzoff \& Moore, 1977). Infants become capable of imitating meaningful communicative gestures by the age of 10 months (Masur, 2006). Procedural imitation, the copying of novel acts on objects, is seen from the age of 6 months (Barr, Dowden, \& Hayne, 1996). Infants fromthe age of 9 months imitate parts of action sequences on objects (Elsner, Hauf, \& Aschersleben, 2007). From the age of 1 year they imitate familiar and novel two- and three-act sequences on objects (Bauer \& Mandler, 1992). Ten-month-olds imitate acts with an appropriate object, e.g., drinking from a cup (Užgiris, 1981). From the age of 14 months, children imitate novel and seemingly irrational acts with objects, substituted acts such as touching a box with the head instead of the hands to switch on a light (Meltzoff, 1988). From the age of 22 months, children imitate acts with a socially inappropriate or substituted object, e.g., drinking from a car (Užgiris, 1981). In developmental, cognitive and social psychology research, imitation is seen as a window into the sensorimotor, cognitive and social abilities of young children, including thosewith atypical development, in particular childrenwith autismspectrum disorders (ASD) (Rogers \&Williams, 2006). In a comprehensive review Williams,Whiten, and Singh (2004) pooled the findings fromwell-controlled case-control studies, involving 196 individualswith ASD. They calculated the combined p-value of group differences with respect to imitation problems to an appropriate control group, resulting in a p-value of .00002 . The size of the imitative problem was most apparent in younger age groups (Williams, Whiten, \& Singh, 2004). However, a clear picture of imitative abilities in childrenwith ASD is confounded by the heterogeneity of the clinical phenotype (Levy,Mandell, \& Schultz, 2009), the lack of a consistent and operational definition of imitation, thewide variability across the types ofimitation tasks and the absence of a comprehensive standardized imitation battery for children (Sevlever \& Gillis, 2010). Such a measure should include familiar andunfamiliar tasks, taskswith andwithoutobjects, goal-directedandnon-goal-directed tasks, tasks requiring tool use, and facial and gestural imitation tasks (Sevlever \& Gillis, 2010). There are currently four published measures (Ayres, 1989; Berge's \&Le' zine, 1963; Korkman, Kirk, \& Kemp, 1997; Užgiris \& Hunt, 1987) that are frequently used in clinical settings to assess imitation abilities in young disabled children. Although these measures rely on a theoretical framework and prove consistency of the scores, they consider imitation as a onedimensional construct and are limited to bodily imitation (Ayres, 1989; Berge's \& Le' zine, 1963; Korkman et al., 1997) or their construct validity regarding distinct domains of imitation was never investigated (Užgiris \& Hunt, 1987). Therefore, the purpose of this study was to develop the Preschool Imitation and Praxis Scale (PIPS) designated to be a reliable and valid multidimensional instrument to measure the accuracy of imitation performance of preschool children. 


\subsection{Theoretical framework of the Preschool Imitation and Praxis Scale (PIPS)}

The multifaceted components of imitation are supported by clinical and empirical accounts of brain lesion studies in adults that have been reported over the last century. Neuropsychologists went on investigating different action types (e.g., meaningful and non-meaningful, transitive and intransitive, opaque and transparent, uni- and bimanual) to unravel the existence of putative mechanisms involved in imitation problems and apraxia (Petreska, Adriani, Blanke, \& Billard, 2007). A prominent model of imitation and the assumed neural underpinnings addressing this issue rely on current cognitive neuroscience and brain imaging studies in healthy and apraxic adults. Based on a series of studies conducted in the laboratory, Rumiati and colleagues tested the "dual route hypothesis of imitation", according to which imitation is not accomplished by a unique operation but by two different mechanisms (Carmo \& Rumiati, 2009; Rumiati \& Tessari, 2002; Rumiati et al., 2005; Tessari, Canessa, Ukmar, \& Rumiati, 2007; Tessari \& Rumiati, 2004;). The study with healthy adults revealed that speeded imitation was significantly more accurate for meaningful (e.g., hammering) than for non-meaningful gestures (e.g., by modifying the relationship between the hand-arm and the trunk of the hammering action) when they were presented in separate lists, suggesting that two different routes were used. When the two types of gestures were presented intermingled, the advantage of meaningful over non-meaningful imitation disappeared, suggesting that participants selected the same route for imitating both stimulus types (Tessari \& Rumiati, 2004). Similar behavioural patterns were observed in unilateral brain-damaged patients (Tessari et al., 2007). Hence, the group of Rumiati assumed the existence of two distinctive routes of imitation regarding the representational content of the gestures and two differential neural mechanisms. The first is the imitation of non-meaningful and/or novel unfamiliar gestures of which the goal can only be identified retrospectively. This imitative performance can only take a direct route, bypassing long-term memory and transforming visuospatial characteristics directly into motor representations. Results of PET-studies in healthy (Rumiati et al., 2005) and apraxic adults (Tessari et al., 2007) revealed that this direct imitation mechanism involves visuospatial transformation processes by activation of areas belonging to the dorsal stream. The second is the imitation of meaningful and/or familiar, and/or well-trained gestures for which the observer can identify a meaning or a goal and possesses a template in the long-term memory. This indirect imitation mechanism involves semantic processing by activation of areas belonging to the ventral stream (Rumiati et al., 2005; Tessari et al., 2007). Recently, these researchers found that imitation performance among healthy adults engaged in a speeded imitation task was significantly poorer when meaningful gestures involved objects (e.g., hammering with an imaginary hammer), rather than no objects (e.g., waving good-bye), suggesting that the use of objects increases processing demands (Carmo \& Rumiati, 2009).

\subsection{Construction and description of the Preschool Imitation and Praxis Scale (PIPS)}

Based on a deductive test construction approach, we selected action types for the Preschool Imitation and Praxis Scale (PIPS) considered to be important on the basis of the above mentioned theoretical ground of the dual-route theory of imitation (Carmo \& Rumiati, 2009; Rumiati \& Tessari, 2002; Rumiati et al., 2005; Tessari et al., 2007; Tessari \& Rumiati, 2004) and the influence of action types as unravelled in research in apraxic adults (Petreska et al., 2007). First, we have selected action types with different effects. The effect of bodily imitation (i.e., of actions without objects, either gestural or facial) is by definition internal. The child observes hand postures and facial expressions and must generate a matching posture or facial expression. In contrast, the effect of procedural imitation (i.e., of actions with objects) is by definition external. It causes salient effects and environmental changes. Second, we have selected action types with different representational levels: meaningful and nonmeaningful bodily imitation tasks, goal directed and non-goal directed procedural imitation tasks. Copying a 
meaningful or goal-directed action involves a proper discrimination of the features of the action, the comprehension of the meaning of the action and the linkage to previous knowledge about the result of the perceived action. If the child understands the meaning of an action, the action is probably familiar to the child. Previous experience with the action to be imitated can contribute to the imitation performance. Meaningful gestures, transitive as well as intransitive, are symbolic. Transitive gestures with an imaginary object (e.g., to pretend to comb your hair with an imaginary comb) demonstrate a certain level of symbolisation and knowledge of the object and tool use. Although an imaginary object is used, transitive gestures are goal directed. Intransitive gestures without an imaginary object are communicative gestures (e.g., to wave good-bye). In contrast to meaningful and goal-directed actions, children are not acquainted with non-meaningful and non-goal-directed actions, which rely on perceptual motor processes of accurate discrimination and duplication of the features of the action. By definition, nonmeaningful and non-goal-directed actions are always novel and unknown. Third, we have selected action types with different temporal complexities: single and sequential. Sequences demand a temporal organisation of familiar or unfamiliar acts. Finally, we have selected action types with different visual monitoring possibilities. When the child imitates perceptually transparent gestures and hand postures, the child can see his/her own hands and can use visual monitoring to achieve the match, even though his/her visual perspective on the own and the demonstrator's hands is different. When the child copies facial expressions and opaque gestures and hand postures, the child observes the examiner's but not his/her own face and hands. It is plausible that facial and opaque gestural imitations are founded on cross-modal guidance. Combinations of these action characteristics resulted in ten task categories of the PIPS: six gestural, three procedural and one facial (Table 1). The six task categories of gestural imitation are: meaningful intransitive gestures (i-MG; e.g., communicative gestures such as 'perform the gesture to wave good-bye'); meaningful goal directed transitive gestures (t-MG; e.g., 'pretend to comb your hair with an imaginary comb'); non-meaningful single hand postures (si-NMG; e.g., 'raise your outstretched arm till 908 anteflexion and make a fist'); non-meaningful bimanual hand postures (biNMG; e.g., 'place one fist on top of the other'); non-meaningful hand postures to the face and head (fa-NMG; e.g., 'touch the top of your nose with the extended index finger'); non-meaningful sequences of hand postures (sqNMG; e.g., 'hit the table with the palm of your hands, cross the arms and hit the table again, return to the original position and hit the table once more'). The three task categories of procedural imitation are: goal directed substituted actions upon objects (sao-P; e.g., 'raise a toy bear by pulling a cord'), goal directed actions upon substituted objects (aso-P; e.g., 'turn a cup upside-down and play drums on it with two spoons') and non-goal directed action sequences upon objects (sq-P; e.g., 'open a box, put the lid on the table, turn the box upsidedown, put a block on the bottom of the box'). There is one facial imitation category (f; e.g., 'shake the head, eyes closed to say "no" with an expression of disapproval'). Facial expressions have a communicative meaning. For each task category, we have selected 4 imitation tasks, which are possible to be performed by young children, but unlikely to be exhibited spontaneously (see appendix for details of the 40 PIPS items). 


\section{Methods}

\subsection{Participants}

\subsubsection{Sample of typically developing preschoolers $(n=498)$}

To achieve a sample representative of a typical mainstream population of preschool children, a stratified random sampling procedure of day-care centres and regular preschools in Flanders, the Dutch-speaking region within Belgium, was used. Criteria for admission into the study were that the children were not born preterm (more than 36 weeks gestation age and birth weight above $1500 \mathrm{~g}$ ) and had no known physical, sensory, or mental handicap according to the parental report in the Ages and Stages Questionnaires (ASQ) (Bricker \& Squires, 1999). The ASQ is a parent-administered structured questionnaire that covers five domains of child development: communication, gross motor, fine motor, problem-solving and personalsocial skills. The ability of the ASQ system to correctly identify typically developing children (specificity) is high: $86 \%$. The ability to detect delayed development (sensitivity) is on average: $72 \%$ (Bricker \& Squires, 1999). The mean time interval between the parental report and the test was three weeks. In total 498 children between 12 and 59 months of age (51.2\% females and $48.8 \%$ males) were involved (Table 2). The socio-economic status (SES) of the children was determined by the educational level of mother and father expressed in educational years: level 1 (less than 7 years), level 2 (7-10 years), level 3 (11-12 years), level 4 (13-16 years) and level 5 (more than 16 years). The combined educational level of both parents was used as an indicator for the child's SES. The distribution of the combined SES scores was as follows: score 2 in $0.4 \%$; score 3 in $2.1 \%$; score 4 in $5.8 \%$; score 5 in $5.8 \%$; score 6 in 24.3\%; score 7 in 17.3\%; score 8 in 20.6\%; score 9 in $10.3 \%$ and score 10 in $13.4 \%$ of the children. The parents of all typically developing children signed an informed consent prior to participation of their child.

Table 1

Ten task categories and action characteristics of the Preschool Imitation and Praxis Scale (PIPS).

\begin{tabular}{|c|c|c|c|c|c|}
\hline Task category & $\begin{array}{l}\text { Action } \\
\text { type }\end{array}$ & $\begin{array}{l}\text { Representat } \\
\text { ional level }\end{array}$ & $\begin{array}{l}\text { Temporal } \\
\text { organisati } \\
\text { on }\end{array}$ & $\begin{array}{l}\text { Visual } \\
\text { monitoring } \\
\text { possibility }\end{array}$ & Effect \\
\hline $\begin{array}{l}\text { Intransitive meaningful } \\
\text { gestures (i-MG) }{ }^{\mathrm{a}}\end{array}$ & Gestural & $\begin{array}{l}\text { Meaningful } \\
\text { (communicativ } \\
\text { e) }\end{array}$ & Single & $\begin{array}{l}\text { Transparent } \\
\text { (hands) }\end{array}$ & Internal \\
\hline $\begin{array}{l}\text { Transitive meaningful } \\
\text { gestures (t-MG) }\end{array}$ & Gestural & $\begin{array}{l}\text { Meaningful } \\
\text { (goal directed) }\end{array}$ & Single & $\begin{array}{l}\text { Transparent } \\
\text { (hands) }\end{array}$ & Internal \\
\hline $\begin{array}{l}\text { Single non-meaningful } \\
\text { hand postures (si-NMG) }\end{array}$ & Gestural & $\begin{array}{l}\text { Non- } \\
\text { meaningful }\end{array}$ & Single & $\begin{array}{l}\text { Transparent } \\
\text { (hands) }\end{array}$ & Internal \\
\hline $\begin{array}{l}\text { Bimanual non-meaningful } \\
\text { hand postures (bi-NMG) }\end{array}$ & Gestural & $\begin{array}{l}\text { Non- } \\
\text { meaningful }\end{array}$ & Single & $\begin{array}{l}\text { Transparent } \\
\text { (hands) }\end{array}$ & Internal \\
\hline $\begin{array}{l}\text { Non-meaningful hand } \\
\text { postures to the face or } \\
\text { head (fa-NMG) }\end{array}$ & Gestural & $\begin{array}{l}\text { Non- } \\
\text { meaningful }\end{array}$ & Single & Opaque & Internal \\
\hline $\begin{array}{l}\text { Sequences of non- } \\
\text { meaningful hand } \\
\text { postures (sq-NMG) }\end{array}$ & Gestural & $\begin{array}{l}\text { Non- } \\
\text { meaningful }\end{array}$ & Sequence & $\begin{array}{l}\text { Transparent } \\
\text { (hands) }\end{array}$ & Internal \\
\hline Substituted actions upon & Procedural & Goal directed & Single & Transparent & External \\
\hline
\end{tabular}




\begin{tabular}{|l|l|l|l|l|l|}
\hline Task category & $\begin{array}{l}\text { Action } \\
\text { type }\end{array}$ & $\begin{array}{l}\text { Representat } \\
\text { ional level }\end{array}$ & $\begin{array}{l}\text { Temporal } \\
\text { organisati } \\
\text { on }\end{array}$ & $\begin{array}{l}\text { Visual } \\
\text { monitoring } \\
\text { possibility }\end{array}$ & Effect \\
\hline objects $($ sao-P) & & & & $\begin{array}{l}\text { (hands and } \\
\text { objects) }\end{array}$ & \\
\hline $\begin{array}{l}\text { Actions upon substituted } \\
\text { objects (aso-P) }\end{array}$ & Procedural & Goal directed & Sequence & $\begin{array}{l}\text { Transparent } \\
\text { (hands and } \\
\text { objects) }\end{array}$ & External \\
\hline $\begin{array}{l}\text { Sequences of non- } \\
\text { meaningful actions upon } \\
\text { objects (sq-P) }\end{array}$ & Procedural & $\begin{array}{l}\text { Non-goal } \\
\text { directed }\end{array}$ & Sequence & $\begin{array}{l}\text { Transparent } \\
\text { (hands and } \\
\text { objects) }\end{array}$ & External \\
\hline Facial expressions (f) $)^{j}$ & Facial & $\begin{array}{l}\text { Meaningful } \\
\text { (communicativ } \\
\text { e) }\end{array}$ & Single & Opaque & Internal \\
\hline
\end{tabular}

${ }^{a}$ For example, perform the gesture to wave good-bye.

${ }^{\mathrm{b}}$ For example, pretend to comb your hair with an imaginary comb.

${ }^{\mathrm{c}}$ For example, raise your outstretched arm till $90^{\circ}$ anteflexion and make a fist.

${ }^{d}$ For example, place one fist on top of the other.

${ }^{e}$ For example, touch the top of your nose with the extended index finger.

${ }^{f}$ For example, hit the table with the palm of your hands, cross the arms and hit the table again, return to the original position and hit the table once more.

${ }^{9}$ For example, raise a toy bear by pulling a cord.

${ }^{\mathrm{h}}$ For example, turn a cup upside-down and play drums on it with two spoons.

${ }^{i}$ For example, open a box, put the lid on the table, turn the box upside-down, put a block on the bottom of the box.

${ }^{j}$ For example, shake the head, eyes closed to say "no" with an expression of disapproval.

\subsubsection{Sample of preschoolers with autism spectrum disorders (ASD) $(n=47)$}

Forty-seven preschoolers with ASD between 1.9 and 4.5 years of age (mean chronological age CA of 40.5 months, SD 9.1 months), 12 female and 35 male, were diagnosed according to a multidisciplinary clinical consensus classification (University Autism Clinics, Flanders) in addition to a positive ADOS-G-classification. The Autism Diagnostic Observation Schedule-Generic (ADOS-G) is a semi-structured, play based assessment which provides systematic probes for autism symptoms in social interaction, communication, play, and repetitive behaviours and interests (Lord, Rutter, DiLavore, \& Risi, 2003). The ADOS-G was administered by trained investigators. The children were free from any medical condition and had no visual or hearing impairment. Nonverbal mental level was measured with the use of the Dutch modification of the Bayley Scales of Infant Development (BSID-II-NL - nonverbal mental) (Van der Meulen, Ruiter, Lutje Spelberg, \& Smrkovsky, 2000) or the revised version of the Snijders-Oomen Nonverbal Intelligence Test for Children (SON-R 2.5-7) (Tellegen et al., 1998). Language reception and production level were measured with the use of the Dutch version of the MacArthur-Bates Communicative Development Inventories (N-CDI) (Zink \& Lejaegere, 2002) or the Reynell 
Developmental Language Scales (RTOS) (Schaerlaekens, Zink, \& Van Ommeslaeghe, 2003). Gross and fine motor level were measured with the use of the locomotor, respectively visuomotor integration subtest of the Peabody Developmental Motor Scales-2 (PDMS-2) (Folio \& Fewell, 2000). The parents of all children with ASD signed an informed consent prior to participation of their child. This part of the study was approved by the ethics committees of the University Hospitals Louvain, Antwerp, Brussels and Ghent (Flanders) before the collection of data.

\subsection{Procedure}

The children were assessed by trained examiners. The PIPS-training took $5 \mathrm{~h}$ and was spread over two weeks. During the first session, the trainer (M.V.) explained the item instructions and the scoring system. A first training video was observed. During the second session, the examiners were given feedback on their test administration. Three other training videos were scored independently. An interrater agreement of the total score above $85 \%$ with the trainer was achieved by all examiners. The children were individually assessed in a quiet room. Before administering the 40 tasks of the PIPS, a child was given three exercises: the imitation of 'removing five beads one by one from a string and putting them in a cup'; 'clapping the hands', and 'raising an open hand'. During these introductory tasks, a broad range of instructions to evoke imitation was given to the child: demonstrations, verbal commands, physical assistance.

Table 2

Descriptive statistics and comparison of ages: total sample $(n=498)$.

\begin{tabular}{|c|c|c|c|c|c|c|c|c|}
\hline \multirow[t]{2}{*}{ Age (months) } & \multicolumn{3}{|c|}{ Females } & \multicolumn{3}{|c|}{ Males } & \multicolumn{2}{|c|}{ Independent samples } \\
\hline & $n$ & $\begin{array}{l}\text { Mean age } \\
\text { (months) }\end{array}$ & $\begin{array}{l}\text { S } \\
\mathbf{D}\end{array}$ & $n$ & $\begin{array}{l}\text { Mean age } \\
\text { (months) }\end{array}$ & $\begin{array}{l}\text { S } \\
\text { D }\end{array}$ & & \\
\hline $12-23 \mathrm{~m}(n=88)$ & 44 & 19.4 & $\begin{array}{l}3 . \\
4\end{array}$ & 44 & 19.4 & 3.0 & $t=0.00$ & $p=1.0$ \\
\hline $\begin{array}{l}24-35 \mathrm{~m} \\
(n=138)\end{array}$ & 65 & 29.8 & 3. & 73 & 29.3 & 3.7 & $t=0.82$ & $p=0.40$ \\
\hline $\begin{array}{l}36-47 \mathrm{~m} \\
(n=150)\end{array}$ & 81 & 40.8 & $\begin{array}{l}3 . \\
2\end{array}$ & 69 & 41.6 & 3.6 & $t=-1.35$ & $p=0.17$ \\
\hline $\begin{array}{l}48-59 \mathrm{~m} \\
(n=122)\end{array}$ & 65 & 52.7 & $\begin{array}{l}3 . \\
3\end{array}$ & 57 & 52.9 & 3.0 & $t=-0.44$ & $p=0.65$ \\
\hline Sample $(n=498)$ & 255 & 37.3 & 12 & 24 & 36.5 & $\begin{array}{l}12 . \\
3\end{array}$ & $t=0.73$ & $p=0.46$ \\
\hline
\end{tabular}


The 40 tasks of the PIPS were presented in a standardized way, e.g., left and right handed actions were demonstrated alternately. The child was free to imitate with the left- or right hand. Before demonstrating each task, a child's attention was attracted by addressing the child by name. Only the verbal instruction "(Name), you do this too" was given. The time needed to complete the PIPS ranged from 10 to 20 min. Imitation performance was immediately scored on a 3 or 5 point scale in accordance with the criteria of the scoring system of the PIPS (Vanvuchelen, 2009), which evaluated the spatiotemporal resemblance between the modelled and copied action. The final PIPS score was a reflection of the accuracy of the child's imitation performance.

\subsection{Data analysis}

\subsubsection{Internal construct validity}

An exploratory factor analysis (EFA) was conducted using principal-axis factoring in SPSS (Version 14) on the 40 initial PIPS items to explore underlying imitation dimensions. Kaiser-Meyer-Olkin measure of sampling adequacy (KMO) was calculated for individual and multiple variables. Values above 0.9 were considered as excellent (Field, 2005). The percentage of non-redundant residuals with absolute values above .05 should be less than $50 \%$ (Field, 2005). To minimize subjectivity, three factor selection criteria were used to have a sufficient number of factors: (1) the Kaiser's criterion, since the sample size in this study exceeded 250 and the average communalities were greater than 0.60; (2) the Cattell's scree plot and (3) the interpretability criterion (Field, 2005). Promax rotation with Kaiser normalisation was used, because some action characteristics were common in some task categories. In EFA, factor loadings are generally considered to be meaningful when they exceed .30 or .40 (Field, 2005). To determine inclusion in a dimension, a score above .35 on a primary loading of items after rotation was used as cut off. To verify the robustness of the obtained conclusions two alternative analyses have been performed. A second EFA was conducted with a reduced set of tasks. Since the present study includes a large standardisation sample, it provides withinsample replication opportunities. The sensitivity analysis was also done by repeating the same procedure in a random sample of $50 \%$ out of the 498 children.

\subsubsection{Internal consistency}

Cronbach's alpha coefficient was calculated to determine the degree of homogeneity among the PIPS tasks. Cronbach's alpha of .80 may be considered acceptable. Between .80 and .89 the level of clinical significance is good; and when it is .90 and above it is excellent (Cicchetti, 1994).

\subsubsection{Association with child characteristics}

In the typically developing sample, the association between socio-economic status (SES) and imitation performance was measured using a Spearman's rank correlation coefficient. Differences between imitation performances of female and male participants were calculated using an independent samples t-test. In both samples, the association between chronological age and the PIPS scale score and domain scores was calculated using a Pearson's product-moment correlation coefficient. 


\subsubsection{Criterion-related validity}

The PIPS scale score of the children with ASD was compared with their score on mental, language and motor developmental measures using a Pearson's product-moment correlation coefficient.

\section{Results}

\subsection{Internal construct validity}

$\mathrm{KMO}$ was 0.98 , indicating that factor analysis (EFA) should yield distinct and reliable factors. There were $9 \%$ nonredundant residuals with absolute values greater than .05 . Four factors were extracted with an eigenvalue greater than 1 . They explained $66.6 \%$ of the variance of the PIPS-data. The Cattell's scree plot confirmed visually the four factors. Table 3 presents the promax-rotated factor pattern matrix.

The first factor (eigenvalue $=22.62$ ) explained most of the variance $(56.6 \%$ ) and consisted of 21 items involving all nonmeaningful single (si-NMG), bimanual (bi-NMG) and hand postures to the face (fa-NMG), all meaningful intransitive (i-MG) and transitive (t-MG) gestures (with exception of 'pointing to the ceiling' i-MG2 and 'pretend to hit an imaginary nail with an imaginary hammer' t-MG2), as well as all facial tasks (with exception of $\mathrm{f} 4$ 'to pout with a distressed facial expression'). The common characteristic of the items of factor 1 was the temporal organisation, in particular single bodily imitation. The finding that this domain explained the greatest part of the variance might be partly due to the fact that a relatively large number of items in the PIPS addressed this issue. The second factor (eigenvalue $=1.55$ ) explained an additional $3.9 \%$ of the variance and consisted of 9 items involving all substituted actions upon objects (sao-P) and all actions upon substituted objects (aso-P) as well as the intransitive meaningful gesture 'pointing to the ceiling' (i-MG2). Obviously, when children pointed to the ceiling, they experienced the ceiling as an object and pointing was for them as a goal directed action to this object. The common characteristics of the items of factor 2 were the visual monitoring on the hands and objects, as well as the goal directed content. Therefore, this factor was interpreted as goal directed procedural imitation. The third factor (eigenvalue $=1.23$ ) explained an additional $3.1 \%$ of the variance and consisted of 6 items involving all non-meaningful sequences of hand postures (sq-NMG), the transitive meaningful gestures 'to pretend to hit an imaginary nail with an imaginary hammer' (t-MG2) and the facial expression 'to pout with a distressed facial expression'. At first sight, there was no common characteristic of the items, but something else occurred. Instead of performing 'hit an imaginary nail with an imaginary hammer' in one single action as demonstrated by the examiner, children performed this action sequentially. First they imitated the hammering action and at a later stage they placed the other hand in the right place. Children reproduced the facial expression 'to pout with a distressed facial expression' also in sequence instead of as one single act. In contrast to the examiner, they protracted the lower lip first and then frowned their brows. The common characteristic of the items of factor 3 was the consecutive temporal organisation. Therefore, this factor was interpreted as sequential bodily imitation. The fourth factor (eigenvalue $=1.21$ ) explained an additional $3.0 \%$ of the variance and consisted of 4 items involving all sequences of actions upon objects (sq-P), characterised by visual monitoring on the hands and the objects, non-goal directed content and a sequential organisation. This factor was interpreted as non-goal directed procedural imitation. The task 'open the box, take a block out of it, put it on the table, and close the box' (sq-P1) was assumed to be a non-goal directed action to an object, but children seemed to experience this action both as a goal directed and non-goal directed one. A second EFA was conducted with a reduced set of items. Items with the lowest loading in their category were excluded, 
in particular fa-NMG3, bi-NMG2, si-NMG1, sao-P4, aso-P4, sq-NMG3, t-MG2, f4 or with a factor loading above .40 on two factors, in particular i-MG2, sq-P1. KMO was 0.97 . Four factors were extracted with an eigenvalue greater than 1 . They explained $68.1 \%$ of the variance of the PIPS-data. The 30 PIPS tasks formed the same, but more coherent subscales compared to the former model. The first factor (eigenvalue $=17.06$ ) explained most of the variance (56.8\%) and consisted of all single bodily imitation tasks: meaningful intransitive (i-MG) and transitive (t-MG) gestures; non-meaningful single (si-NMG), bimanual (bi-NMG) and hand postures to the face (fa-NMG) and facial tasks (factor loadings ranged from .42 to .88). The second factor (eigenvalue $=1.2$ ) explained an additional $4.2 \%$ of the variance and consisted of all goal directed procedural imitation tasks: substituted actions upon objects (sao-P) and actions upon substituted objects (aso-P) (factor loadings ranged from .50 to .93). The third factor (eigenvalue $=1.1$ ) explained an additional $3.7 \%$ of the variance and consisted of all non-meaningful sequences of hand postures (sq-NMG) (factor loadings ranged from .74 to .92). The fourth factor (eigenvalue = 1.04) explained an additional $3.4 \%$ of the variance and consisted of all non-goal directed sequences of actions upon objects (sq-P) (factor loadings ranged from .66 to .78). A third EFA was conducted with the reduced set of items in a random sample of $50 \%$ out of the 498 children and confirmed this pattern matrix. These results confirmed the four relatively distinct imitation domains.

\subsection{Internal consistency}

Cronbach's alpha for the remaining 30 items was excellent (aPIPS SCALE $=0.97$ ) and the same was true for the 18 single bodily imitation items (aSUBSCALE $1=0.96$ ). Cronbach's alpha for the 6 goal directed procedural imitation items (aSUBSCALE $2=0.88$ ) and the 3 sequential bodily imitation items (aSUBSCALE $3=0.84$ ) was good. For the 3 non-goal directed procedural imitation items Cronbach's alpha was fair (aSUBSCALE $4=0.79$ ).

\subsection{Association with child characteristics}

In the typically developing sample ( $\mathrm{n}=498)$, no significant correlation between the combined SES score and PIPS scale score of the remaining 30 items was found ( $r s=\ldots 0.07, p=0.13$ ). The same was true for the subscales scores $\left(r s=\_0.07, p=0.13 ; r s=\_0.06, p=0.20 ; r s=\_0.04, p=0.40 ; r s=\_0.09, p=0.40\right.$ respectively). No sex difference on the PIPS scale score $(t=1.68, p=0.09)$ and subscale scores was found $(t=$ 1.91, $\mathrm{p}=0.06 ; \mathrm{t}=0.55, \mathrm{p}=0.58 ; \mathrm{t}=1.31, \mathrm{p}=0.19$, and $\mathrm{t}=1.06, \mathrm{p}=0.29$ respectively). The association between chronological age of the typically developing children and the PIPS scale score of the remaining 30 items and subscale scores was substantial and positive: for the PIPS-scale $r=0.79, p<0.001$; for SUBSCALE $1 r=0.78, p$ $<0.001$; for SUBSCALE $2 r=0.60, p<0.001$; for SUBSCALE $3 r=0.61, p<0.001$ and for SUBSCALE $4 r=$ $0.71, \mathrm{p}<0.001$. 
Table 3

Promax-rotated factor pattern matrix of the 40 items of Preschool Imitation and Praxis Scale (PIPS) $(n=498)$.

\begin{tabular}{|c|c|c|c|c|}
\hline & $\begin{array}{l}\text { Factor } 1 \\
\text { Single } \\
\text { gestural and } \\
\text { facial } \\
\text { Imitation }\end{array}$ & $\begin{array}{l}\text { Factor } 2 \\
\text { Goal directed } \\
\text { procedural } \\
\text { imitation }\end{array}$ & $\begin{array}{l}\text { Factor } 3 \\
\text { Sequential } \\
\text { gestural and } \\
\text { facial imitation }\end{array}$ & $\begin{array}{l}\text { Factor } 4 \\
\text { Non-goal } \\
\text { directed } \\
\text { procedural } \\
\text { imitation }\end{array}$ \\
\hline bi-NMG3 & .88 & -.04 & -.08 & .03 \\
\hline bi-NMG1 & .87 & .05 & -.11 & .08 \\
\hline bi-NMG4 & .85 & .009 & -.11 & 15 \\
\hline $\mathrm{f3}$ & .85 & -.04 & -.02 & .04 \\
\hline fa-NMG4 & .85 & -.16 & .03 & .12 \\
\hline fa-NMG2 & .84 & -.10 & -.01 & .08 \\
\hline si-NMG3 & .84 & .01 & -.06 & -.02 \\
\hline i-MG4 & .83 & .16 & -.09 & -.10 \\
\hline si-NMG4 & .81 & -.09 & .05 & .06 \\
\hline fa-NMG1 & .78 & .21 & -.16 & .02 \\
\hline fa-NMG3 & .75 & -.13 & .03 & 16 \\
\hline bi-NMG2 & .75 & .06 & .03 & .06 \\
\hline si-NMG2 & .73 & -.06 & .03 & .09 \\
\hline i-MG3 & .68 & .17 & .03 & -.006 \\
\hline $\mathrm{f1}$ & .65 & -.02 & .17 & .02 \\
\hline si-NMG1 & .62 & .28 & .02 & -.06 \\
\hline i-MG1 & .59 & .31 & .01 & -07 \\
\hline t-MG1 & .52 & .12 & .24 & -.08 \\
\hline t-MG3 & .47 & .35 & .09 & -.13 \\
\hline f2 & .45 & .02 & .31 & .04 \\
\hline t-MG4 & .36 & .32 & .28 & -.09 \\
\hline sao-P3 & -.12 & .93 & -.04 & .08 \\
\hline sao-P1 & -.18 & .85 & -.15 & .26 \\
\hline sao-P2 & .18 & .66 & .04 & -.11 \\
\hline aso-P2 & .05 & .58 & .03 & .22 \\
\hline aso-P1 & .05 & .55 & 10 & .14 \\
\hline sao-P4 & 13 & .51 & .04 & .21 \\
\hline i-MG2 & .47 & .48 & .05 & -.25 \\
\hline aso-P3 & .15 & .44 & .08 & .24 \\
\hline aso-P4 & .20 & .36 & 15 & .24 \\
\hline sq-NMG4 & -.17 & -.07 & .97 & .11 \\
\hline sq-NMG2 & -.08 & .001 & .90 & -.002 \\
\hline sq-NMG1 & .01 & .02 & .76 & .05 \\
\hline sq-NMG3 & 35 & -.15 & .51 & 16 \\
\hline $\mathrm{t}-\mathrm{MG} 2$ & .22 & .30 & .46 & -.19 \\
\hline $\mathrm{f4}$ & 32 & .07 & .39 & -.02 \\
\hline
\end{tabular}




\begin{tabular}{|l|l|l|l|l|}
\hline & $\begin{array}{l}\text { Factor 1 } \\
\text { Single } \\
\text { gestural and } \\
\text { facial } \\
\text { Imitation }\end{array}$ & $\begin{array}{l}\text { Factor 2 } \\
\text { Goal directed } \\
\text { procedural } \\
\text { imitation }\end{array}$ & $\begin{array}{l}\text { Factor 3 } \\
\text { Sequential } \\
\text { gestural and } \\
\text { facial imitation }\end{array}$ & $\begin{array}{l}\text { Factor 4 } \\
\text { Non-goal } \\
\text { directed } \\
\text { procedural } \\
\text { imitation }\end{array}$ \\
\hline & -10 & -002 & .10 & .69 \\
\hline sq-P2 & .20 & -.06 & .10 & .69 \\
\hline sq-P3 & -.11 & .43 & -.09 & .61 \\
\hline sq-P1 & .13 & .19 & .007 & .60 \\
\hline sq-P4 & $3.9 \%$ & $3.1 \%$ & $3.0 \%$ \\
\hline Explained variance & $56.6 \%$ & & \\
\hline Factorian
\end{tabular}

Factor loadings with an absolute value $>.35$ are in boldface.

In the sample of children with ASD $(n=47)$, the association between chronological age and the PIPS scores was substantial and positive for the PIPS scale $r=0.56, p<0.001$; for SUBSCALE $1 r=0.61, p<0.001$; for SUBSCALE $2 r=0.31, p=0.03$ and for SUBSCALE $3 r=0.50, p<0.001$. This was not the case for SUBSCALE $4 r=0.23, p=0.11$.

\subsection{Criterion-related validity}

In the sample of children with ASD ( $n=47)$, the association between the PIPS scale score and nonverbal mental age $(r=0.73, p<0.001)$, receptive $(r=0.66, p<0.001)$ and expressive $(r=0.61, p<0.001)$ language age, gross $(r=0.59, p<0.001)$ and fine $(r=0.74, p<0.001)$ motor age were substantial and positive.

\section{Discussion}

This study is the first to describe the development and validation of a multidimensional measure of imitation aptitude in preschool children. Although research findings of behavioural studies in children and results of neuroscience and brain imaging studies in adults revealed a multidimensional nature of imitation, existing imitation instruments for children do not take this in account. To overcome this shortcoming, models of imitation from adult studies were used as theoretical framework for the construction of the Preschool Imitation and Praxis Scale (PIPS). The methodology of manipulating task characteristics allowed the implementation of different underlying processes of imitation (Petreska et al., 2007). The 10 task categories of the PIPS were generated by systematically manipulating: (1) the action types which were classified as gestural, facial and procedural and which were an indication of the nature of the effect of the action, external versus internal, as well as an indication of the underlying visual monitoring on the hand or objects in transparent versus opaque actions; (2) the representational level of the actions which was an indication of two distinctive routes of imitation, in particular the direct perception-action conversion route for non-meaningful and non-goal directed actions and the indirect, semantic-mediated route for meaningful and goal directed actions; (3) the temporal organisation of the actions, in particular single versus sequences of actions. 


\subsection{Internal construct validity}

Internal construct validity explores the underlying traits of a scale and the extent to which these are reflected in the theoretical construct on which the scale is based. Factor analysis on the original 40 items of the PIPS revealed four distinct subscales of imitation tasks. Results of factor analysis on 30 out of 40 items of the PIPS revealed the same subscales, but in a more consistent manner. The advantage of this shorter form is a reduced test administration time. The subscales were labelled single versus sequential bodily imitation and goal directed versus non-goal directed procedural imitation. Bodily imitation is commonly used for gestural and facial imitation. The four relatively distinct subscales of imitation tasks in the PIPS confirm that imitation in young children is a polymorphous phenomenon and covers a range of domain-specific mechanisms. Firstly, the absence or presence of objects seems to play a pivotal role in imitation functions and strategies children use. To imitate bodily actions, children interact face-to-face with the adult in a dyadic condition. Bodily imitation produces an internal social 'likeme' experience. Procedural imitation produces salient external effects on the environment. To imitate actions upon objects, children focus their attention simultaneously on the adult and the objects. This triadic situation is linked to joint attention behaviour, such as gaze following and social referencing (Tomasello \& Carpenter, 2007). The finding in the present study that children experience the imitation of pointing and watching to the ceiling as an action to an object rather than a communicative gesture, is in line with this idea. Secondly, the meaning of an action seems to play a prominent role in procedural imitation. Children seem to perceive the examiner as a goal directed agent. The comprehension of the meaning of an observed action upon an object allows children to make inferences about others' behaviours and intentions during the social learning process. In contrast to non-goal directed procedural actions, actions upon substituted objects and substituted actions upon objects can be perceived as if the examiner is pretending. Rakoczy demonstrated that by 2-3 years of age, children perceive pretending as a type of intentional activity (Rakoczy, Tomasello, \& Striano, 2004). Surprisingly, meaningful and non-meaningful bodily imitation items loaded on the same factors. This finding suggests that the meaning of an action does not seem to play an important role in bodily imitation. One could argue that children between 1 and 4.9 years of age do not necessarily understand the meaning of the transitive and intransitive gestures of the PIPS. Children spontaneously perform the selected gestures around the age of 16 months (Zink \& Lejaegere, 2002). An alternative explanation could be that children had used the same strategy to imitate meaningful and nonmeaningful bodily actions. The PIPS includes more non-meaningful than meaningful bodily actions and all actions are presented in a mixed list. Studies with adults suggest that in these conditions, all gestures may be treated as if they are non-meaningful (Rumiati et al., 2005; Tessari et al., 2007; Tessari \& Rumiati, 2004). Thirdly, the temporal organisation of single and sequential actions seems to play a central role in bodily imitation. Imitation of action sequences shows whether children are able to make the perception-action conversion not only in one, but in several action steps. This suggests that bodily imitation, regardless of the meaning behind the actions, is merely founded on direct perception-action conversions, including the temporal organisation of the actions. In the factor analysis, transparent and opaque bodily imitation tasks were withheld under the same factor. This finding is consistent with the results of the study of Gleissner and colleagues. They investigated how 3-year-olds imitated gestures by manipulating four task characteristics: visual monitoring, spatial endpoint, movement path and number of hands. Results of their study showed no difference as a function of whether the children could visually monitor their own responses or not (Gleissner, Meltzoff, \& Bekkering, 2000). Children's imitation can be divided in at least two levels of imitation depending on the contents of actions. First, to imitate the mixed list of bodily acts and to copy non-goal directed procedural acts, children may have used the direct route of imitation. They may have faithfully copied the directly observable motor organisation of the examiner's acts, i.e., the means and result of the act, without the need to understand its meaning or goal. Imitation of actions of which goal can only be identified retrospectively can only take a direct route, bypassing long-term memory and transforming visuospatial 
characteristics directly into motor representations. In terms of human brain activity, children may have activated areas belonging to the dorsal stream. To copy goal directed actions upon objects, children may have used the semantic-related indirect route of imitation. For instance: when the examiner demonstrated "put a toy car in bed, turn it upside-down and tuck it in with a blanket", children may have identified the goal, possessed a template in their long-term memory and may have thought "the examiner is doing this odd behaviour as if the toy car is a doll". In that case, they may have copied the nonobservable, but inferable higher organisational structures of the examiner's act, i.e., the examiner's goal and intention. In terms of human brain activity, children may have activated areas belonging to the ventral stream.

\subsection{Internal consistency}

The high internal consistency of the PIPS scale score and subscale scores indicates that the items measure the same construct.

\subsection{Association with child characteristics}

A further objective of this study was to examine the relationship between imitation performance and characteristics of the children. The positive and strong associations between the children's age and the PIPS scale score and subscales scores revealed that the PIPS has the potential to measures developmental changes in different imitation domains in typically and atypically developing young children.

\subsection{Criterion-related validity}

The positive and strong associations between the PIPS scale score and scores on mental, language and motor measures in children with autism spectrum disorders supported criterion-related validity.

\subsection{Limitations and directions for further research}

A critical remark has to be made. Because principal-axis factoring is an exploratory technique, the conclusions that can be drawn from this method are limited. Findings should be replicated in other samples of preschool children. Directions for further research include: (1) the investigation of the suitability of the procedural imitation tasks to differentiate between imitative learning and learning by non-imitative example-following; (2) the expansion of the sample of typically developing children to derive PIPS age-equivalent scores; (3) the investigation of the imitation development of intellectually disabled preschoolers associated with spared imitation (e.g., Down's syndrome) and (4) the investigation of the diagnostically utility of the PIPS in children suspected of autism, in particularly sensitivity and specificity analyses of the PIPS scores for the diagnosis of autism. 


\section{Acknowledgments}

This study was supported by a Foundation Marguerite-Marie Delacroix grant to M. Vanvuchelen. We would like to thank all children, parents, staff of the University Clinics of Antwerpen, Brussel, Gent and Leuven (Belgium) who participated in this research, as well as the following students: Nicole Hermans and Kenneth Willems (PHL University College, Belgium), Kim Abrams (Department of Rehabilitation Sciences, K.U.Leuven, Belgium) and Nana Frempong (Centre for Statistics, University of Hasselt, Belgium).

Appendix A. Description of the 40 items of the Preschool Imitation and Praxis Scale (PIPS) presented in standardized order

\begin{tabular}{|c|c|c|c|c|}
\hline $\begin{array}{l}\text { It } \\
\mathrm{e} \\
\mathrm{m} \\
\mathrm{nr} \\
-\end{array}$ & $\begin{array}{l}\mathbf{T} \\
\mathbf{y} \\
\mathbf{p} \\
\mathrm{e} \\
-\end{array}$ & $\begin{array}{l}\text { Cat } \\
\text { ego } \\
\text { ry }\end{array}$ & Task description & $\begin{array}{l}\text { S } \\
\text { co } \\
\text { re } \\
\end{array}$ \\
\hline $\begin{array}{l}\text { PIP } \\
\text { S1 }\end{array}$ & $P$ & $\begin{array}{l}\text { sao- } \\
\text { P1 }\end{array}$ & Raise a toy bear by pulling a cord & $0-2$ \\
\hline $\begin{array}{l}\mathrm{PIP} \\
\mathrm{S} 2\end{array}$ & P & $\begin{array}{l}\text { sao- } \\
\text { P2 }\end{array}$ & Put a wooden block on top of your head & $0-2$ \\
\hline $\begin{array}{l}\text { PIP } \\
\text { S3 }\end{array}$ & $P$ & $\begin{array}{l}\text { sao- } \\
\text { P3 }\end{array}$ & Switch on a lamp in a toy animal with your forehead & $0-2$ \\
\hline $\begin{array}{l}P I P \\
S 4\end{array}$ & $P$ & $\begin{array}{l}\text { sao- } \\
\text { P4 }\end{array}$ & Knock down a tower of wooden blocks with your elbow & $0-2$ \\
\hline $\begin{array}{l}\mathrm{PIP} \\
\text { S5 }\end{array}$ & G & i- & Perform the gesture to "wave good-bye" & $0-2$ \\
\hline $\begin{array}{l}P I P \\
\text { S6 }\end{array}$ & $G$ & i- & Perform the gesture to "point with your index finger to the ceiling" & $0-2$ \\
\hline $\begin{array}{l}\text { PIP } \\
\text { S7 }\end{array}$ & G & i- & $\begin{array}{l}\text { Perform the gesture to "show something with an outstretched hand in } \\
\text { supination" }\end{array}$ & $0-2$ \\
\hline $\begin{array}{l}\mathrm{PIP} \\
\text { S8 }\end{array}$ & G & i- & Perform the gesture to "beckon with the index finger" & $0-2$ \\
\hline $\begin{array}{l}P I P \\
\text { S9 }\end{array}$ & $G$ & $\begin{array}{l}\text { Si- } \\
\text { NMG } \\
1\end{array}$ & Raise your outstretched arm till $90^{\circ}$ anteflexion and make a fist & $0-3$ \\
\hline $\begin{array}{l}\text { PIP } \\
\text { S10 }\end{array}$ & G & $\begin{array}{l}\text { Si- } \\
\text { NMG } \\
2\end{array}$ & $\begin{array}{l}\text { Raise your outstretched arm till } 90^{\circ} \text { anteflexion and make a circle with } \\
\text { the index finger and thumb }\end{array}$ & $0-3$ \\
\hline $\begin{array}{l}\text { PIP } \\
\text { S11 }\end{array}$ & G & $\begin{array}{l}\text { Si- } \\
\text { NMG } \\
3\end{array}$ & $\begin{array}{l}\text { Raise your outstretched arm till } 90^{\circ} \text { anteflexion and stretch out your } \\
\text { fingers }\end{array}$ & $0-3$ \\
\hline $\begin{array}{l}\text { PIP } \\
\text { S12 }\end{array}$ & $\mathrm{G}$ & $\begin{array}{l}\text { Si- } \\
\text { NMG } \\
4\end{array}$ & $\begin{array}{l}\text { Raise your outstretched arm till } 90^{\circ} \text { anteflexion, hold up the little finger } \\
\text { while all the other fingers and the thumb are bent }\end{array}$ & $0-3$ \\
\hline $\begin{array}{ll}P I P \\
\text { S13 }\end{array}$ & $P$ & $s q-P 1$ & Open the box, take a block out of it, put it on the table, close the box & $0-3$ \\
\hline $\begin{array}{l}\text { PIP } \\
\text { S14 }\end{array}$ & $P$ & sq-P & $\begin{array}{l}\text { Open the box, put the lid on the table, turn the box upside-down, put } \\
\text { the block on the bottom of the box }\end{array}$ & $0-3$ \\
\hline
\end{tabular}




\begin{tabular}{|c|c|c|c|c|}
\hline $\begin{array}{l}\text { lt } \\
\text { e } \\
\text { m } \\
\mathrm{nr}\end{array}$ & $\begin{array}{l}\mathbf{T} \\
\mathbf{y} \\
\mathbf{p} \\
\mathrm{e} \\
-\end{array}$ & $\begin{array}{l}\text { Cat } \\
\text { ego } \\
\text { ry }\end{array}$ & Task description & $\begin{array}{l}\text { S } \\
\text { co } \\
\text { re } \\
\end{array}$ \\
\hline $\begin{array}{l}\text { PIP } \\
\text { S15 }\end{array}$ & $P$ & sq-P3 & $\begin{array}{l}\text { Take the block from the bottom of the box, turn the box in normal } \\
\text { position again, close the box, put the block on the lid of the box }\end{array}$ & $0-3$ \\
\hline $\begin{array}{l}\text { PIP } \\
\text { S16 }\end{array}$ & $P$ & sq-P4 & $\begin{array}{l}\text { Take the block from the lid of the box, open the box, put a disc into the } \\
\text { box, close the box, put the block again on the lid of the box }\end{array}$ & $0-3$ \\
\hline $\begin{array}{l}\text { PIP } \\
\text { S17 }\end{array}$ & G & MG1 & Pretend to "comb your hair with an imaginary comb" & $0-4$ \\
\hline $\begin{array}{l}\text { PIP } \\
\text { S18 }\end{array}$ & $G$ & t- & Pretend to "hit an imaginary nail with an imaginary hammer" & $0-4$ \\
\hline $\begin{array}{l}\text { PIP } \\
\text { S19 }\end{array}$ & G & t- & Pretend to "open an imaginary door with an imaginary key" & $0-4$ \\
\hline $\begin{array}{l}\text { PIP } \\
\text { S20 }\end{array}$ & G & t- & Pretend to "brush your teeth with an imaginary toothbrush" & $0-4$ \\
\hline $\begin{array}{l}\text { PIP } \\
\text { S21 }\end{array}$ & G & $\begin{array}{l}\mathrm{Bi}- \\
\mathrm{NMG} \\
1\end{array}$ & Place one fist on top of the other & $0-3$ \\
\hline $\begin{array}{l}\text { PIP } \\
\text { S22 }\end{array}$ & $G$ & \begin{tabular}{l|}
$\mathrm{Bi}-$ \\
$\mathrm{NMG}$ \\
2
\end{tabular} & $\begin{array}{l}\text { Stretch out both arms in front of you, one hand is open, one hand is } \\
\text { closed }\end{array}$ & $0-3$ \\
\hline $\begin{array}{l}\text { PIP } \\
\text { S23 }\end{array}$ & G & $\begin{array}{l}\mathrm{Bi}- \\
\mathrm{NMG} \\
3\end{array}$ & $\begin{array}{l}\text { Extend the index fingers of both hands while the other fingers and } \\
\text { thumbs are bent, and bring the top of the index fingers towards each } \\
\text { other }\end{array}$ & $0-3$ \\
\hline $\begin{array}{l}\text { PIP } \\
\text { S24 }\end{array}$ & G & $\begin{array}{l}\mathrm{Bi}- \\
\mathrm{NMG} \\
4\end{array}$ & $\begin{array}{l}\text { Open one hand in vertical position and touch the top of the fingers with } \\
\text { the palm of the other hand in horizontal position }\end{array}$ & h-3 \\
\hline $\begin{array}{l}\text { PIP } \\
\text { S25 }\end{array}$ & G & $\begin{array}{l}\text { Fa- } \\
\text { NMG } \\
1\end{array}$ & Extend your index finger and touch the top of your nose & $0-3$ \\
\hline $\begin{array}{l}\text { PIP } \\
\text { S26 }\end{array}$ & G & $\begin{array}{l}\text { Fa- } \\
\text { NMG } \\
2\end{array}$ & Touch your lower lips with the nails of your thumbs & $0-3$ \\
\hline $\begin{array}{l}\text { PIP } \\
\text { S27 }\end{array}$ & $G$ & $\begin{array}{l}\text { fa- } \\
\text { NMG } \\
3\end{array}$ & Open your hand and touch your forehead with your thumb & $0-3$ \\
\hline $\begin{array}{l}\text { PIP } \\
\text { S28 }\end{array}$ & G & $\begin{array}{l}\text { Fa- } \\
\text { NMG } \\
4\end{array}$ & $\begin{array}{l}\text { Extend the index finger of your left hand and touch your right cheek } \\
\text { and extend the index finger of your right hand and touch your left } \\
\text { cheek }\end{array}$ & $0-3$ \\
\hline $\begin{array}{l}\text { PIP } \\
\text { S29 }\end{array}$ & $P$ & $\begin{array}{l}\text { aso- } \\
\mathrm{P} 1\end{array}$ & Turn a cup upside-down and play drums on it with two spoons & $0-2$ \\
\hline $\begin{array}{l}\text { PIP } \\
\text { S30 }\end{array}$ & P & $\begin{array}{l}\text { aso- } \\
\text { P2 }\end{array}$ & Remove the cap of a doll and put a shoe on the head of the doll & $0-2$ \\
\hline $\begin{array}{l}\text { PIP } \\
\text { S31 }\end{array}$ & $P$ & $\begin{array}{l}\text { aso- } \\
\text { P3 }\end{array}$ & Put a toy car in bed, turn it upside-down and tuck it in with a blanket & $0-2$ \\
\hline $\begin{array}{l}\text { PIP } \\
\text { S32 }\end{array}$ & $P$ & $\begin{array}{l}\text { aso- } \\
\text { P4 }\end{array}$ & $\begin{array}{l}\text { Place a bottle in horizontal position, put a doll like a rider on the bottle, } \\
\text { take a ride }\end{array}$ & $0-2$ \\
\hline
\end{tabular}




\begin{tabular}{|c|c|c|c|c|}
\hline $\begin{array}{l}\text { It } \\
\text { e } \\
\mathrm{m} \\
\mathrm{nr} \\
-\end{array}$ & $\begin{array}{l}T \\
y \\
p \\
e \\
-\end{array}$ & $\begin{array}{l}\text { Cat } \\
\text { ego } \\
\text { ry } \\
\end{array}$ & Task description & $\begin{array}{l}\text { S } \\
\text { co } \\
\text { re } \\
\end{array}$ \\
\hline $\begin{array}{l}\text { PIP } \\
\text { S33 }\end{array}$ & & $\begin{array}{l}\text { sq- } \\
\text { NMG } \\
1\end{array}$ & $\begin{array}{l}\text { Hit the table with the palm of your hands, cross the arms and hit the } \\
\text { table again, return to the original position and hit the table once more }\end{array}$ & $0-3$ \\
\hline $\begin{array}{l}\text { PIP } \\
\text { S34 }\end{array}$ & & $\begin{array}{l}\text { sq- } \\
\text { NMG } \\
2\end{array}$ & $\begin{array}{l}\text { Hit the table with one hand in supination, turn the hand in pronation } \\
\text { and hit the table again, clap in the hands, hit the table with the palm of } \\
\text { both hands }\end{array}$ & $0-3$ \\
\hline $\begin{array}{l}P I P \\
\text { S35 }\end{array}$ & & $\begin{array}{l}s q- \\
N M G \\
3\end{array}$ & $\begin{array}{l}\text { Hit the table with the fist of one hand, hit the table with the palm of the } \\
\text { same hand, repeat this with the other hand }\end{array}$ & $0-3$ \\
\hline $\begin{array}{l}\text { PIP } \\
\text { S36 }\end{array}$ & & $\begin{array}{l}\text { sq- } \\
\text { NMG } \\
4\end{array}$ & $\begin{array}{l}\text { Hit the table with both hands in supination, turn the hands in pronation, } \\
\text { hit the table again, clap in the hands, hit the table with the palm of both } \\
\text { hands once more }\end{array}$ & $0-3$ \\
\hline PIP & & f1 & $\begin{array}{l}\text { Shake the head, eyes closed to say 'no', with an expression of } \\
\text { disapproval }\end{array}$ & $0-2$ \\
\hline PIP & & $\mathrm{f} 2$ & Look angry with a frown of the eyebrows & $0-2$ \\
\hline $\begin{array}{l}\text { PIP } \\
\text { S39 }\end{array}$ & & f3 & Nod quickly with your head and show an expression of happiness & $0-2$ \\
\hline \begin{tabular}{|l|l|}
$P I P$ \\
$S 40$
\end{tabular} \mid & & F4 & Pout with an aggrieved expression & $0-2$ \\
\hline
\end{tabular}

Full-size table

P, procedural; G, gestural; F, facial; sao-P, substituted-actions-upon-objects; i-MG, intransitive meaningful gestures; si-NMG, single non-meaningful hand postures; sq-P, action-sequences-upon-objects; t-MG, transitive meaningful gestures; bi-NMG, bimanual non-meaningful hand postures; fa-NMG, non-meaningful hand postures to the face or head; aso-P, actions-upon-substituted-objects; sq-NMG, sequences of non-meaningful hand postures; $f$, imitation of facial expressions.

The 10 tasks which were excluded through exploratory factor analysis are in italics font. 


\section{References}

Ayres, J. A. (1989). Sensory integration and praxis test (SIPT). Los Angeles: Western Psychological Services.

Barr, R., Dowden, A., \& Hayne, H. (1996). Developmental changes in deferred imitation by 6- to 24-month-old infants. Infant Behavior and Development, 19, 159- 170.

Bauer, P. J., \& Mandler, J. M. (1992). Putting the horse before the cart: The use of temporal order in recall of events by one-year-old children. Developmental Psychology, 28, 441-452.

Berge 's, J., \& Le' zine, I. (1963). Test d'imitation de gestes. Techniques d'explorations du sche'ma corporel et des praxis chez l'enfant de 3 a` 6 ans. Paris: Masson.

Bricker, D., \& Squires, J. (1999). Ages \& Stages Questionnaires (ASQ). A parent-completed, child-monitoring system (second ed.). Baltimore: Paul H Brookes Publishing Co.

Carmo, J. C., \& Rumiati, R. I. (2009). Imitation of transitive and intransitive actions in healthy individuals. Brain Cognition, 69, 460-464.

Cicchetti, D. V. (1994). Guidelines, criteria, and rules of thumb for evaluating normed and standardized assessment instruments in psychology. Psychological Assessment, 6, 284-290.

Elsner, B., Hauf, P., \& Aschersleben, G. (2007). Imitating step by step: A detailed analysis of 9- to 15-month-olds' reproduction of a three-step action sequence. Infant Behavior \& Development, 30, 325-335.

Field, A. (2005). Discovering statistics using SPSS (second ed.). London: Sage Publications.

Folio, M. R., \& Fewell, R. R. (2000). Peabody Developmental Motor Scales, Second Edition. Guide to item Administration. Austin, TX: Pro-Ed.

Gleissner, B., Meltzoff, A. N., \& Bekkering, H. (2000). Children's coding of human action: Cognitive factors influencing imitation in 3-year-olds. Developmental Science, 3, 405-414.

Korkman, M., Kirk, U., \& Kemp, S. (1997). NEPSY—Developmental neuropsychological assessment. San Antonio: The Psychological Corporation.

Levy, S. E., Mandell, D. S., \& Schultz, R. T. (2009). Autism. Lancet, 374, 1627-1638.

Lord, C., Rutter, M., DiLavore, P., \& Risi, S. (2003). Autism diagnostic observation schedule. Manual. Los Angeles, CA: Western Psychological Services.

Lyons, D. E., Young, A. G., \& Keil, F. C. (2007). The hidden structure of overimitation. Proceedings of the National Academy of Sciences of the United States of America, 104, 19751-19756.

Meltzoff, A. N., \& Moore, M. K. (1977). Imitation of facial and manual gestures by human neonates. Science, 198, 75-78.

Masur, E. F. (2006). Vocal and action imitation by infants and toddlers during dyadic interactions: Development, causes and consequences. In S. J. Rogers \& J. H. G. 
Williams (Eds.), Imitation and the social mind. Autism and typical development. New York: The Guilford Press. pp. $27-47$.

Meltzoff, A. N. (1988). Infant imitation after a 1-week delay: Long-term memory for novel acts and multiple stimuli. Developmental Psychology, 24, 470-476.

Petreska, B., Adriani, M., Blanke, O., \& Billard, A. G. (2007). Apraxia: A review. Progress in Brain Research, 164, 61-83.

Prinz, W. (2002). Experimental approaches to imitation. In A. N. Meltzoff \&W. Prinz (Eds.), The imitative mind: development, evolution, and brain bases. Cambridge: Cambridge University Press. pp. 143-162.

Rakoczy, H., Tomasello, M., \& Striano, T. (2004). Young children know that trying is not pretending: a test of the "behaving-as-if" construal of children's early concept of pretense. Developmental Psychology, 40, 388-399.

Rogers, S. J., \& Williams, J. H. G. (2006). Imitation and the social mind. Autism and typical development. New York: The Guilford Press.

Rumiati, R. I., \& Tessari, A. (2002). Imitation of novel and well-known actions: The role of short-term memory. Experimental Brain Research, 142, 425-433.

Rumiati, R. I., Weiss, P. H., Tessari, A., Assmus, A., Zilles, K., Herzog, H., \& Fink, G. R. (2005). Common and differential neural mechanisms supporting imitation of meaningful and meaningless actions. Journal of Cognitive Neuroscience, 17, 1420-1431.

Schaerlaekens, A., Zink, I., \& Van Ommeslaeghe, K. (2003). Reynell Taalontwikkelingsschalen. RTOS. Handleiding. Lisse: Swets Test Publishers.

Sevlever, M., \& Gillis, J. M. (2010). An examination of the state of imitation research in children with autism: Issues of definition and methodology. Research in Developmental Disabilities, 31, 976-984.

Tellegen, P., Winkel, M., Wijnberg-Williams, B., \& Laros, J. (1998). Snijders-Oomen Niet-verbale Intelligentietest. SON-R 2-7. Handleiding en Verantwoording. Lisse: Swets Test Publishers.

Tessari, A., Canessa, N., Ukmar, M., \& Rumiati, R. I. (2007). Neuropsychological evidence for a strategic control of multiple routes in imitation. Brain, 130, 1111-1126.

Tessari, A., \& Rumiati, R. I. (2004). The strategic control of multiple routes in imitation of actions. Journal of Experimental Psychology: Human Perception and Performance, 30, 1107-1116.

Tomasello, M., \& Carpenter, M. (2007). Shared intentionality. Developmental Science, 10, 121-125.

Tomasello, M., Carpenter, M., Call, J., Behne, T., \& Moll, H. (2005). Understanding and sharing intentions: The origins of cultural cognition. Behavioral and Brain Sciences, 28, 675-691.

Užgiris, I. C. (1981). Two functions of imitation during infancy. International Journal of Behavioral Development, 4, 1-12.

Užgiris, I. C., \& Hunt, J. M. (1987). Infant performance and experience. New findings with the ordinal scales. Urbana: University of Illinois Press. 
Van der Meulen, B. F., Ruiter, S. A. J., Lutje Spelberg, H. C., \& Smrkovsky, M. (2000). Bayley Scales of Infant Development, Nederlandse versie. BSID-II-NL. Lisse: Swets Test Publishers.

Vanvuchelen, M. (2009). Imitation problems in children with autism spectrum disorders. A study of their nature, clinical significance and utility in diagnosis. Ph.D. Dissertation in Rehabilitation Sciences and Physiotherapy, Group of Biomedical Sciences, Katholieke Universiteit Leuven, Belgium.

Williams, J. H., Whiten, A., \& Singh, T. (2004). A systematic review of action imitation in autistic spectrum disorder. Journal of Autism and Developmental Disorders, 34, 285-299.

Zink, I., \& Lejaegere, M. (2002). N-CDIs, Lijsten voor Communicatieve Ontwikkeling. Aanpassing en hernormering van de MacArthur CDIs van Fenson et al. Leuven: Acco. 